the pronounced hysteria was directly responsible for the unfortunate results.

An inquiry as to the time of development of the disturbances is perhaps of some interest. Of the 51 cases with hereditary influence the manifestation of the nervous condition was apparent in nearly every instance before the recognition of the tuberculosis, but was very frequently aggravated subsequently. Of the 37 in whom no family history of neurotic taint could be discovered, 10 may be considered safely to have exhibited rather pronounced symptoms before the onset of the tuberculosis but which became more marked later; 12 only after the development, or coincidently with it, and 15 unknown. Apparently the effect of the tuberculosis has been to render the preexisting nervous disturbance more pronounced, to increase the susceptibility to such influences in those already predisposed by inheritance, and to provide the appropriate conditions for the acquired development, i. e., impaired nutrition, mental depression and auto-intoxication. Likewise, the previous existence of well-marked functional nervous derangement can but afford added opportunities for the development of tuberculosis, from the lessened resistance of the individual, and hence the increased receptivity of the soil to the agent of infection. Impaired general nutrition, while frequently a result, is also undoubtedly a potent factor in the causation of each diseased condition.

With reference to climatic influence, it may be stated that in almost no case were the manifestations of nervous disorder displayed for the first time in Colorado. Thirty-four cases suffered an aggravation in this State. Of these, 9 were rendered worse only temporarily and later improved satisfactorily in this respect. Twelve exhibited greater nervous disturbance coincidently with a corresponding loss of the tubercular condition, with increased impairment of strength and general nutrition. Seven presented exacerbations to be referred solely to sufficient external causes capable of application anywhere, as excessive dissipation, extreme burden of business cares, and unfortunate domestic relations. The remaining 6 became worse, from a neurologic point of view, in the absence of any apparent cause. Of the entire number (34) rendered more nervous, either temporarily or permanently after arrival, 19 died as a result of the pulmonary infection or have grown worse. The balance at the present time are showing varying degrees of improvement. Nine of these have made a remarkable gain in all respects, despite decided norvous disturbances.

Finally, of the 45 cases previously alluded to as having exhibited distinct pulmonary improvement, 39 showed an ultimate gain in the nervous disorder, and of the 63 cases showing no permanent loss, or doing well from the neurologic standpoint, 39 have improved with reference to the tuberculosis. Thus the results are:

Improved in both conditions

Cases.

Improved in tubercular but not in nervous condition. 6

Improved in nervous but not in tubercular condition. 24

No improvement in either.

The reasonable interpretation of this would appear to be, that the influence of the climate upon the nervous condition had been particularly advantageous in a large proportion of the cases, presumably by virtue of the pulmonary improvement secured with the increased nutrition. It is also evident that the climate has been not unfavorable, to say the least, for the considerable number who either showed an improvement or no change neurologically, notwithstanding a progressive loss in the tubercular disease. These conclusions are of interest in view of the oft-repeated assertion that the co-existence of nervous manifestations contraindicates a recourse to the Colorado climate for the consumptive. The statement of the alleged aggravation of the nervous condition with the result. ing unfavorable influence upon the course of the pulmonary disease, presupposes the hypothesis that improvement in the functional disturbance must precede arrestment of the tubercular infection, and at the same time advances the argument that the nervous derangement is of more essential consideration than the tuberculosis. It has been my observation that the nervous disturbances have diminished almost invariably in proportion to the degree of arrestment and the gain in the general strength. I am convinced that the majority of cases temporarily aggravated, or even developed early after arrival, are due in great measure to purely psychical influences, as enforced absence from family and friends, inability to immediate adaptation to strange surroundings, and previously accepted theories as to probable climatic effects. Such cases usually respond favorably later to rational and appropriate management. It should, however, be conceded, I think, that occasionally certain cases, especially those with strong inherent tendencies and severe manifestations, do poorly, particularly in the high altitudes of Colorado. These cases have been comparatively few in my own experience.

While the existence of pronounced nervous conditions in pulmonary tuberculosis constitutes a factor of grave prognostic moment in any location, it would seem that the climatic consideration of the tubercular infection per se should be regarded as of paramount importance. I would also insist that the especial significance of functional nervous disturbance in pulmonary invalids, should be to add further emphasis to the necessity of strict personal attention to details of management, environment and mode of life.

\section{A FASCICLE OF CASES IN SUGGESTIVE} (HYPNOTIC) THERAPEUTICS.

Presented to the Section on Neurology and Medical Jurisprudence, at the Forty-ninth Annual Meeting of the American Medical Association held at Denver, Colo., June 7-10, 1898.

BY H. S. DRAYTON, M.D. NEW YORK CITY.

The American medical world has sbown itself easily affected, as a rule, by the current of events, medical and surgical, in Europe. The experiments of Koch with tuberculin, of Klebs, Loeffler and Roux with antitoxin, and the various suggestions with reference to organic extracts-cerebral, testicular, thyroid, etc.that have crossed the Atlantic have received a ready attention, in some cases developing into a wave of enthusiasm, and have found practical recognition in employment by many of our progressive medical brethren. I would refer merely to the disappointment that some have experienced in applying these more or less authoritative procedures, and remark en passant, that the wisest of us are subject to mistake occasionally through the very earnestness of our desire to wrest from old Mors one at least of his dreaded instrumentalities for human decimation.

In view of the readiness of the American profession 
to entertain foreign advice in therapeutics it seems inconsistent with that quality of mind that one well accredited modus has not aroused interest enough to have it accorded a fair trial. I refer to the hypnotic procedure, or what is otherwise termed suggestive therapeusis. I am sure that all who listen to these remarks have learned something of hypnotism, and whatever the opinion they may entertain concerning it the fact is conspicuous that for several years this form or variety of psychologic medicine has had its hospital or dispensary establishments in Austria, Germany and France, and names of wide reputation, like those of Benedikt, Kraft-Ebing, Charcot, Delboef, Binet and Bernhein, are associated with it. Some American physicians have ventured to treat patients in this manner, but it would appear that with a few exceptions they were merely experimenting, and too distrustful of results to make the method a real part of their professional equipment. Some, too, I judge to be tender on the side of reputation, apprehensive that they might be regarded as giving sanction to "a superstition," as hypnotism was rather vaguely termed recently by the editor of one of our periodicals. I can scarcely believe that any one here gives heed to the medieval nonsense that sensational and unscientific writers offer to the unlearned public under the title of hypnotism or mesmerism.

Having given several years to the observation of the phenomena of suggestion I have come to the conclusion that the hypnotic state is consistent with the human physiology, and not to be regarded as determining a positive pathologic phase of either mind or body, although its induction may prove valuable as an aid in diagnosis, I have also reached the conclusion that in hypnotic suggestion we have at our hands an agency, the power of which is not fully realized, for the treatment of many forms of disease. In this statement I merely confirm the utterance of many writers from the time of Braid and Esdaile to the present.

I shall proceed to give some account of a few cases from my notes of those patients whose maladies commanded more than ordinary consideration. Let me assume that those present are sufficiently familiar with the common methods of inducing hypnosis, although for my own part I can not say that I have any particular method. One of my earliest experiences was recorded about nine years ago:

Case 1.-Frank S., a young man 28 years old, came to me with a history of epileptic attacks dating back to his fifteenth year. His physiognomy, the spare figure, angular hatchet face, dark, acne-spotted skin, dull expression, jerky, irritable movements intimated the chronic epileptic. As the attacks were frequent and often in series, he was incapacitated.for remunerative employment. Then, too, the sequelæ of a fit were becoming more severe and exhausting. $\mathrm{He}$ had been under the treatment of several specialists. Of one remedy he had taken $\$ 400$ worth, according to his father, with alternations of effect, but no decided improvement. Hypnotism had been suggested to the family of Frank, and I was requested to try it, as a dernier ressort. The young man consenting, a trial was made, and at the first interview sufficient control was obtained to warrant going on. My object, it may be unnecessary to say, was to impress the mind of the patient with strong sentiment of opposition to the attacks, to reinforce his will in this behalf, and also to exercise as much personal con trol as possible over such of his habits as needed correction. He was a cigarette smoker, used strong coffee, and was prone to excess in eating, while in some respects his social doings needed amendment. The hypnotic control enabled me to be quite thorough on this side of his life.

The effects of this treatment exceeded my expectations. In a month he began to improve. The attacks occurred less frequently, and his health in every respect showed amendment.
After a time the treatment was given at irreguiar intervals, two or three weeks being allowed to intervene between a sitting, and when the patient's last report was made to me he had had no recurrence of the fits for three months, and had undertaken the transaction of business that required travel and exposure, a venture that previously would have been regarded by his friends as entirely out of consideration. In the course of my observation of this case there were developed certain phenomena that will, I think, be considered extraordinary, even if familiar with hypnotic cases. When the patient first came under notice his attacks occurred without warning. $\mathrm{H}_{\theta}$ would drop suddenly to the floor or ground as if struck by lightning, and on reviving a severe headache usually compelled him to rest a while, if not to sleep. During my treatment if an attack occurred he would be likely to come out of it with little more than a sensation of dullnese that soon wore off. Twice the seizure occurred when I was within ready call, and then, to my surprise, I found that I could, in a few seconds, check the spasm and restore him to consciousness. On one occasion he fell to the floor in the presence of several persons, and was struggling violently when I came to his side. A sweep of my hande from the head to the knee suspended the convulsion and at my command he opened his eyes and rose to his feet, and within ten minutes was able to continue the business transaction he was engaged upon when he fell.

Case 2.-Mrs. E. M. of New Jersey, a woman of 50, of Ger man parentage, vigorous and active, came to me with an account of prolonged attendance upon friends suffering from depressing fevers in epring time. Her appetite had failed, a distressing erythism had supervened rendering her unable to sleep or find repose in any direction. Such medical treatment as she had tried had but increased her distress and restlessness, and further endurance of the condition she declared unbearable. A strong, imperative nature, she seemed at first an unpromising subject for hypnosis, but yielded with comparative ease to the simple procedure of sitting in a comfortable chair and gazing steadily at the white knob of a door four feet or so distant. A brief manipulation of the head deepened the sleep into which she fell in less than ten minutes. Sugges. tions were made with reference to improvement of appetite, the recovery of nerve control and sleep. Two days later a second treatment of a similar nature was given, the lady reporting great improvement in general feeling, having slept well and relished her meals. This improvement was confirmed by the entire recovery of her usual vigor in the course of two weeks. This case is not offered as of an uncommon type.

Case 3.- Miss A., a lady of Boston, about 32, sent to me by her physician. She had suffered with an obscure cerebral malady for sixteen years; tracing it to nervous shock occasioned by a carriage accident. The focus of the disease lay in the situation of the right angular gyrus or anterior margin of the first occipital gyrus. From that point pain, almost constant when not under the influence of anodynes, radiated to all points of the head, being most severe in the course of the right optic nerve and of the great longitudinal sinus. A welleducated lady, with remarkable self-control, she described her symptoms with great clearness. It is an interesting confirmation of the doctrine of localization that her sight, especially in the eye opposite the supposed lesion, had gradually become impaired until she could not read ordinary print or distinguish objects thirty feet away. For relief of the pain, etc., she had visited specialists abroad and at home, and tried, she said, every kind of treatment-even to the late inventions of mental science and faith cure-and although at the suggestion of her last medical adviser she would now request me to try hypnotism she could feel little confidence in that. At the fifth interview Miss A. passed into the state of semi-trance, which state was repeated at the four or five succeding interviews. The procedure in this case was simply to sit by the lady while she reclined upon a lounge, to hold her right hand in one of mine, occasionally to manipulate with great gentleness the forehead; meanwhile commanding her in a mild tone to go to sleep. With this semi-trance came entire relief from pain and abatement in the extreme sensitiveness of the scalp that had been an accompaniment of the malady. Besides the suggestion of relief from the old head misery, I advised the taking of small doses of gelseminum tincture and the application of hot-water compresses to the painful parts. The improvement in this case, as described by the mother and companion-nurse of Miss A. was marvelous. After the third treatment she was able to ride out and endure with comparative comfort the noise and jars of the street. A year later she called at my office and reported that she had had but an occa. sional memory of her old affection, and were it not for her defective vision would consider herself perfectly well.

Case 4.-Rosa P., 33 years old, of Russian birth, dark com- 
plexion, strongly bilious in temperament, well developed muscularly and possessing the powers of endurance usual to her race. The malady was peculiar in its effects; hystero-spinal in origin, with centers of reflex in thelumbar and cervical plexus, it was exhibited chiefly by great tenderness and pain in the lumbar vertebræ and flexur contractures of both hande and of the cervical muscles. The contractures of the hands, when she was brought to we wero apparently permanent, any effort to open them resulting in an intense and painful paroxysm in which the clinch was greatly increased and the arms participating in the flexure. The history of the case included ten years or more of hospital treatment and expert observation. Tho first attack, it was said, had come on unexpectedly when the patient was a girl of 15 . She found her hands disposed to close and could not account for it. Belonging to an intelli gent family, every available means were tried for her relief. In Russia, Austria, Germany and England she had been under treatment by specialists, Professors Benedikt and KrafftEbing among them, a variety of procedures having been uuder taken, with but temporary relief, if any. Hypnotism had been employed, but only under repeated suggestions could the con tractures be reduced for a brief space. Owing to some influ ence that was unpleasant in the hypnosis tuat was commonly produced, it had become objectionable, and the woman at first declined to submit herself to my treatment. However, after a brief interview she consented to a trial and passed easily into complete trance, and at command the hands slowly relaxed. On coming out of the sleep, which was profound, and without any transference of consciousness from one state to the other, the hands remained open and flexible, and continued so, enabling the woman to assist in household duties, etc., for three days, when they closed. Then she came again to me and was relieved of the contraction in the same manner. This woman remained under my observation and treatment for upward of three months, when she went south to live with a married sister. During this time her general health improved; the spinal myalia, which, when I frst saw her, prevented but brief rest in any position besides that of sitting upright, also yielded gradually to the suggestive influence. In a letter received fully two months after her departure from New York she stated that her hands had not closed, although she feared they might, because of her inability to apply to me for treat ment. I should state in this connection that I had little expectation of doing the patient any permanent benefit because of her unfortunate family environment and lack of necessary care. A year later I saw her, she being brought to my office by her relatives, who wished to have her placed in some public or charitable institution. Her physical state had become much worse, but the poor woman, with eyes swimming in tears, held up her hands to show me that they were still open and flexible.

Case 5.-- This case, of a widely differing nature, has a pecu liar interest because of certain phenomena. Mrs. M., a strongly built, energetic brunette of 35 years, attending lectures at one of the medical schools of New York City, came to me in Feb. ruary, 1895. She recounted certain nervous experiences that interfered imperiously with the performance of anatomic studies. She was totally unable to dissect. On entering the room where cadaveric material lay she was seized with a strange nervous excitement that compelled her to withdraw immedi ately, and a distressing sickness followed, the effects of which usually lasted two or more days. The origin of her neurosis she believed to be this: Ten years or so before she came to New York, her father had died suddenly of apoplexy. She was not at home at the time of his death, and on returning was not immediately informed of it, although she know that ho had been very ill. Going into his room, she was surprised to find him lying silent and unresponsive. While she stood at the bed side gazing in speechless anxiety at him, there burst from mouth and nose a stream of blood. This unexpected spectacle terrified her so extremely that for weeks she was subject to hysteric fits and on the border of insanity. For years afterward visions of that blood-stained corpse and bed appeared in her sleep and in her waking hours. A woman of more than ordinary strength of purpose, she had striven against the terrible mem ory, and believed, until she attempted to use the scalpel, that she had nearly overcome the Nemesis of her life. She did not prove an easy subject for hypnosis, but at leugth entered the semi unconscious state - which, I may remark here, is claimed by some writers to be the true hypnotic condition as distin guished from the mesmeric or magnetic trance. As it might be, however, the suggestions for mental calm and self assurance in the performance of anatomic work and other duty were given, and a half dozen sittings of the kind were given. In the course of six weeks Mrs. M. advanced in the degree of selfcontrol until she, as testified by one of her classmates, could handle the instruments of dissection with coolness and facility. During the winter of 189596 this patient reported to me at times, and to the effect that in pursuing her second year of study she had no trouble whatever, and that her recovery from mental dread and solicitude of years was practically assured. Case 6.-Mr. C. A., about 34 years old, by profession a lawyer; of excellent family. The history of the case is imperfect, and it is not necessary to dwell on what may appear to be very probable factors of etiology. Dr. F., who introduced the patient, desired to test the power of suggestion upon a mind confessedly under the influence of a delusion of fear that had continued for some years, and was becoming more accentuated. The patient, a clear.headed and rational man on other subjects, entertained a profound dread of being alone ; would not venture to go from one room to another in his father's house without company, and it was only with great difficulty that he could be persuaded to go out of doors for a few minutes. When brought to my office he was in a state of excitement, with high pulse and pallid face. After some minutes of desultory chat, during which his nerves recovered a state of comparative calmness, I requested Mr. A. to sit in an easy-chair and to gaze as steadily as possible at the lens of a lamp used for laryngoscopic examinations, five or six feet distant; meanwhile I sat by his side holding his left hand in my right, one finger pressing upon the radial artery. At the beginning of the experiment his pulse ran quickly up to 120 , and then gradually fell to 80 , as nearly as I could estimate without consulting a watch. After sitting quietly in the attitude directed, I advised him to relax nerve and muscle as much as possible, giving himself up to a sense of ease and comfort. I gently stroked head and forehead, now and then repeating the admonition to be calm and comfortable. This was the nature of the first interview. At the next interview $A$. exhibited less excitement on entering my office, and a similar procedure was adopted as in the first, suggestions being added relative to the correction of his delusion. Repeated assurances were given of better self control, more steadiness of will, less attention to surroundings, more courage, spirit, independence, self possession, etc. This line of suggestive treatment was continued at succeeding interviews until the fourth, when I commanded him to leave his residence at a certain hour in the afternoon, and walk unattended around the block. This was done, and the circumstance related to me by A. with considerable satisfaction. A few days later he came to my office without attendance. In the meanwhile he had gone with a friend to visit the Hagenbach collection of trained animals, an excursion of two or three miles from his home. The spell under which he had suffered appeared to be broken, for after two more interviews I was informed by bis old physician that an extensive tour in Europe had been arranged on which he (the Doctor) was to accompany Mr. A., and that my fee for services rendered would be honored on sight. Since that time there have been no intimations of a return of the trouble, and Mr. A. is not the candidate for early confinement in an asylum that he had been considered only a few weeks before I first saw him.

\section{REPORT OF A CASE OF RAYNAUD'S DIS-} EASE WITH PATHOLOGIC FINDINGS.

Presented to the Section on Neurology and Medical Jurisprudence, at the Forty-ninth Annual Meeting of the American Medical Association, held at Denver, Colo., June 7-10, 1898.

BY C. EUGENE RIGGS, A.M., M.D. ST. PAUL. HISTORY.

Mrs. M., age 64, weight 195 pounds, American, housewife. Had typhoid fever at age of 19. pneumonia at 53 , measles, whooping cough, diphtheria, acute articular rheumatism at 50 years. Futher died at the age of 76. Mother died at age of 71 of cancer of the breast. Has two sisters living, in average health, and one brother, whereabouts and condition not known. Two years before, the patient had noticed a peculiar numbness of sometimes one finger sometimes another of the left hand, which would last about half an hour. This continued at intervals for over a year. During this period the attacks of numbness came on about once a week, sometimes two mornings consecutively. She was, however, apparently well, when on the even. ing of Feb. 6,1896 , while going upstairs she was sud- 